\title{
Impactos potenciais das alterações no Código Florestal sobre a vegetação de campos rupestres e campos de altitude
}

\author{
Katia Torres Ribeiro ${ }^{1}$ \& Leandro Freitas ${ }^{2,3}$ \\ ${ }^{1}$ Instituto Chico Mendes de Conservação da Biodiversidade, EQSW 103/104, Bloco D, \\ $2^{\circ}$ Andar, CEP 70670-350, Brasília, DF, Brasil \\ ${ }^{2}$ Jardim Botânico do Rio de Janeiro, Rua Pacheco Leão, n. 915, CEP 22460-030, Rio de Janeiro, RJ, Brasil \\ ${ }^{3}$ Autor para correspondência: Leandro Freitas, e-mail: leandro@jbrj.gov.br
}

RIBEIRO, K.T. \& FREITAS, L. Potential impacts of changes to Brazilian Forest Code in campos rupestres and campos de altitude. Biota Neotrop. 10(4): http://www.biotaneotropica.org.br/v10n4/en/ abstract?article+bn04310042010.

\begin{abstract}
The Brazilian campos rupestres and campos de altitude are characterized by mosaics of vegetation types and are better represented above $900 \mathrm{~m}$ in the Espinhaço Range and above 1500-2000 m in the Serra do Mar and Serra da Mantiqueira. They bear high species richness at local and regional scales and numerous relicts and endemisms. These montane refuges, which are of particular interest to conservation in various ways, such as recharge and water regulation, control of erosion and sedimentation, biological singularity and recreational and spiritual values, are facing various threats such as erosion and soil instability, urban and agriculture sprawl, fires, removal of ornamental plants and mining. Moreover, these refuges are among the most vulnerable Brazilian ecosystems to global climate change, because the simple fact that with increasing temperature there is no possibility to migrate to higher altitudes. This paper discusses the potential impacts of the proposed new Brazilian Forest Code, currently under discussion in the Congress, for the conservation of biodiversity in these environments. Particularly we analyze the consequences of the removal of areas above $1800 \mathrm{~m}$ and on the hill tops as Permanent Preservation Areas (APPs), the reducing on the minimum width of the riparian vegetation and the exemption to smallholders of the conservation of native vegetation on their lands ("Legal Reserves"). Such proposals seem to assume that there is great individual injury on behalf of a very diffuse collective benefit, but do not consider the direct benefits of the current instruments of the Code to rural land owners. The losses of biodiversity and ecosystem services (e.g., water supply, presence of pollinators, natural pest control and timber and non-wood resources) with the conversion of habitat that may result from those changes are disproportionate to the potential economic benefit. The instruments proposed on the new Code, ultimately, lead to a model of space occupation with strong contrasts, it means, fully protected areas, such as parks and biological reserves, alternated with extensive areas devoid of vegetation except thin riparian forests. Such a scenario is detrimental to the conservation of biodiversity and for agricultural production, especially to smallholders, who benefit directly from environmental services.

Keywords: endemism, environmental legislation, legal reserve, rural properties, grasslands.
\end{abstract}

RIBEIRO, K.T. \& FREITAS, L. Impactos potenciais das alterações no Código Florestal sobre a vegetação de campos rupestres e campos de altitude. Biota Neotrop. 10(4): http://www.biotaneotropica.org.br/v10n4/ pt/abstract?article+bn04310042010.

Resumo: Campos rupestres e campos de altitude se caracterizam por mosaicos de tipologias vegetais e são mais bem representados acima de 900 m na Cadeia do Espinhaço e acima de 1500-2000 m nas Serras do Mar e Mantiqueira. Apresentam alta riqueza de espécies em escala local e regional e numerosos relictos e endemismos. Esses refúgios montanos, que são de especial interesse para a conservação sob vários aspectos, como recarga e regulação hídrica, contenção da erosão e do assoreamento, singularidade biológica e valores recreativos e espirituais, enfrentam diversas ameaças, como erosão e instabilidade do solo, expansão urbana e agropecuária, queimadas, retirada de plantas ornamentais e mineração; além de estarem entre os ecossistemas brasileiros mais vulneráveis às mudanças climáticas globais, pelo simples fato que com o aumento da temperatura não haverá possibilidade de migração para altitudes mais altas. Neste artigo discutimos impactos potenciais das alterações propostas no substitutivo ao Código Florestal, atualmente em discussão no Congresso Nacional, para a conservação da biodiversidade nesses ambientes. Particularmente analisamos as consequências da supressão de áreas em topos de morros e em altitudes acima de 1800 m como Áreas de Preservação Permanente (APPs), da redução da largura de APPs de matas ciliares e da dispensa de Reserva Legal em pequenas propriedades. Tais propostas parecem partir do princípio de que há grande prejuízo individual em nome de um benefício coletivo muito difuso, mas não consideram os benefícios diretos dos atuais instrumentos do Código aos proprietários, sendo que as perdas de biodiversidade e serviços ambientais (e.g., oferta de água, presença de polinizadores, controladores naturais de pragas e recursos madeireiros e não-madeireiros) com a conversão de habitat que pode advir dessas mudanças são desproporcionais ao potencial benefício econômico. Os instrumentos propostos pelo substitutivo, em última instância, conduzem a um modelo de ocupação do espaço com fortes contrastes, ou seja, áreas integralmente protegidas, como parques e reservas biológicas, alternadas a extensas áreas desprovidas de vegetação nativa, exceto magras matas ciliares. Tal cenário é prejudicial tanto para a conservação da biodiversidade como para a produção agropecuária, principalmente dos pequenos produtores, que se beneficiam diretamente dos serviços ambientais.

Palavras-chave: endemismo, legislação ambiental, reserva legal, módulo rural, vegetação campestre. 


\section{Introdução}

O mais recente relatório da ONU acerca das metas acordadas em 2002 na Convenção sobre Diversidade Biológica (CDB) concluiu que a diversidade de seres vivos no planeta continua a ser desgastada, como resultado das atividades humanas e que as cinco principais pressões que levam à perda da biodiversidade (mudança de habitat, sobrexplotação, poluição, espécies exóticas e mudanças climáticas) se mantêm constantes ou estão aumentando (SCDB 2010). Nenhum país alcançará o cumprimento das metas de conservação da biodiversidade para 2010 e a manutenção das tendências atuais indica potenciais pontos de ruptura na provisão de serviços ecossistêmicos fundamentais, como produção de alimentos e fornecimento de água potável, afetando todas as sociedades, sendo que os pobres tendem a sofrer desproporcionalmente mais, devido a alterações potencialmente catastróficas (SCDB 2010) e pela maior dependência por recursos locais. O conjunto de metas para conservação da biodiversidade é compromisso de todos os governos, incluindo aqueles que não fazem parte da CDB e, portanto, novas propostas ou revisões da legislação ambiental de cada país devem refletir este compromisso.

O Brasil é signatário da $\mathrm{CDB}$ e um de seus maiores defensores. A revisão do Código Florestal (instituído pela Lei 4771/1965, alterado pela Lei 7803/1989 e regulamentado pelo Decreto 5975/2006), que tramita no Congresso Nacional, teve o substitutivo relatado pelo deputado Aldo Rebelo aprovado pela Comissão Especial em julho de 2010. Discutir o Código e propor mudanças é pertinente e válido, uma vez que há normas de significado controverso, como a definição de topo de morro (Cortizo 2007), e dificuldades crônicas, por exemplo, as situações em que as únicas áreas com fertilidade de solos propícia à agricultura estão próximas a riachos. No entanto, como destacado em numerosos fóruns e com ênfase em diferentes grupos biológicos ou regiões e habitats, não é aceitável que alterações na legislação ambiental levem a perda ainda maior da biodiversidade. Para isso é fundamental o envolvimento dos vários setores da sociedade em tais discussões, particularmente da comunidade científica, a qual é geradora de conhecimento relevante para a sustentação dos critérios e parâmetros definidos pelo Código Florestal (Metzger 2010).

Neste artigo procuramos analisar impactos potenciais das alterações propostas no substitutivo ao Código Florestal em discussão no Congresso Nacional sobre a vegetação de campos de altitude e campos rupestres. Os efeitos potenciais das seguintes alterações ao Código são aqui discutidos:

- As áreas com vegetação natural situadas em topo de morros, montes, montanhas e serras e em altitude superior a $1800 \mathrm{~m}$ deixam de ser consideradas como áreas de preservação permanente (APPs). As APPs foram estabelecidas com a função de 'preservar os recursos hídricos, a paisagem, a estabilidade geológica, a biodiversidade, o fluxo gênico de fauna e flora, proteger o solo e assegurar o bem-estar das populações humanas', como citado na lei. Nos termos da legislação atual, a supressão de vegetação em APP somente pode ocorrer em caso de utilidade pública ou de interesse social, devidamente, caracterizados e motivados e quando inexistir alternativa técnica e locacional ou em casos de baixo impacto ambiental e sempre dependente de autorização do órgão ambiental competente e sujeita a medidas mitigadoras e compensatórias;

- Uma nova classe de faixa marginal de vegetação nativa para cursos d'água é estabelecida, a saber, $15 \mathrm{~m}$ de largura para cursos d'água com menos de $5 \mathrm{~m}$ de largura em seu leito menor (i.e., desconsiderando várzea de inundação) (Art. $3^{\circ}$, Ia), reduzindo em $50 \%$ o que vem sendo aplicado até o momento para cursos com estas características;
- A Reserva Legal, reconhecida na legislação atual como 'necessária ao uso sustentável dos recursos naturais, à conservação e reabilitação dos processos ecológicos, à conservação da biodiversidade e ao abrigo e proteção de fauna e flora nativas' (MP 2166-67/2001), deixa de ser obrigatória nas propriedades com extensão de até quatro módulos fiscais (caput Art. 14). Para as demais propriedades, quando a área de reserva legal for inferior ao disposto no Art. 14, pode haver a compensação desta área, na forma de doação de terra dentro de unidade de conservação de proteção integral (Art. 25) ou aquisição de Cota de Reserva Ambiental (Art. 37). As duas possibilidades resultam em proteção a porções territoriais fora da propriedade em questão; e

- Outros dois itens do substitutivo reforçam a pouca importância dada à conservação das formações savânicas e campestres. $\mathrm{O}$ primeiro mantém os percentuais para reserva legal, conforme a fisionomia da vegetação, em $80 \%$ para formações florestais, 35\% para formações savânicas e $20 \%$ para formações campestres na Amazônia Legal e em 20\% para qualquer formação na Mata Atlântica, Cerrado, Caatinga, Pantanal e Pampas. Já em termos de utilidade econômica, são estabelecidas normas para uso das formações florestais (capítulo VII), mas há tênue menção aos recursos não-madeireiros nestas formações, assim como às formações não-florestais, desconsiderando a riqueza de oportunidades de uso sustentável dos recursos naturais destes ambientes (Ribeiro 2005).

\section{A vegetação dos campos rupestres e campos de altitude}

Formações campestres são encontradas em diferentes regiões do Brasil, por exemplo, nos altos das montanhas que se distribuem de forma longilínea acompanhando o litoral (Serras do Mar e da Mantiqueira no sul-sudeste e Serra Geral no sudeste-nordeste), nos pampas sulinos, os campos cerrados e vegetação sobre as chapadas no centro-oeste e as vegetações abertas do norte, como as campinaranas inseridas nas formações florestais amazônicas e os campos altimontanos do escudo das Guianas. Especificamente sobre as montanhas situadas nos terrenos antigos dos planaltos centrais e das serranias costeiras brasileiras, estas alcançam altitudes pouco expressivas (poucas acima de $2000 \mathrm{~m}$ ) em comparação com outras cadeias ainda em elevação, tais como Andes e Himalaia. Tais montanhas apresentam topografias e geologias muito diversas, por exemplo, imensos blocos rochosos aflorados e de distribuição isolada, como os pontões rochosos e "pães de açúcar" capixabas e fluminenses, que podem ultrapassar $1000 \mathrm{~m}$ de desnível, relevos residuais de escarpas alongadas como a Serra do Mar, estruturações alcalinas singulares como o Itatiaia e a extensa cordilheira de cristas quartzíticas do Espinhaço, com suas cimeiras plano-onduladas e vertentes dissecadas (Ab’Saber 1996).

As noções sobre as variações na vegetação dessas montanhas em muito refletem a bem difundida idéia de que o zoneamento da vegetação ao longo do gradiente de altitude repete o zoneamento latitudinal trópico-temperado, culminando na transição de florestas para campos. De fato, em certas escalas, particularmente nos grandes maciços de maior altitude, tal zoneamento vertical ocorre. Além disso, o gradiente altitudinal, por exemplo, é um dos fatores determinantes da elevada diversidade da Mata Atlântica (Oliveira-Filho \& Fontes 2000, Geise et al. 2004). Entretanto, a configuração espacial da flora nas montanhas centro-costeiras brasileiras apresenta numerosas combinações e variações fisionômicas em resposta aos tipos de solo e rocha matriz e características topográficas locais, como continuidade das cimeiras, grau de declividade das escarpas, exposição das encostas e profundidade dos grotões (Giulietti \& Pirani 1988, Ab'Saber 1996, Schaefer et al. 2008). Tais características, somadas aos contatos com 
diferentes domínios (e.g., a face oeste do Espinhaço mineiro voltado para o Cerrado e a face leste para a Mata Atlântica), acarretam em alta diversidade florística e complexa zonação da vegetação, que não se explica apenas pelos gradientes verticais (Ab'Saber 1996, Conceição \& Pirani 2005).

Dessa forma, mais que formações homogêneas, os chamados campos rupestres e campos de altitude (Ferri 1980) se caracterizam por mosaicos de tipologias vegetais e são mais bem entendidos como Complexos Rupestres de Altitude (Benites et al. 2003). Esses complexos estão relacionados à dinâmica paleoclimática quartenária e estão mais bem representados nas elevações acima de $900 \mathrm{~m}$ na Cadeia do Espinhaço e acima de 1500-2000 m nas Serras do Mar e Mantiqueira (Complexos Rupestres de Quartzito e de Granito, sensu Semir 1991), onde se distinguem das formações savânicas ou florestais adjacentes. Grosso modo, incluem matas higrófilas em margens de corpos d'água; cerrado ou matas nebulares e de Araucaria; platôs mais ou menos extensos com arbustais densos e campos compostos por ervas e arbustos de numerosas famílias em matriz graminóide; e plantas epilíticas e "tapetes de monocotiledôneas" (sensu Porembski 2007), com ervas e arbustos associados, sobre as rochas expostas. Tal variabilidade de fitofisionomias contribui fortemente para valores de diversidade beta (i.e., diferença entre habitats) desses complexos.

Campos de altitude e campos rupestres apresentam alta riqueza de espécies em escala local e regional, numerosos relictos e endemismos (Giulietti \& Pirani 1988, Martinelli 1996, Safford 1999a, b, Rapini et al. 2008), incluindo endemismos restritos ou microendemismos, em que são conhecidas apenas populações reduzidas que ocorrem em pequenas áreas com determinadas peculiaridades microambientais (Martinelli 1996, Ribeiro \& Fernandes 2000, Coelho et al. 2007, Rapini et al. 2008). Valores precisos sobre a riqueza de espécies em campos rupestres e campos de altitude como um todo ainda não são disponíveis, mas para exemplo da magnitude dessa biodiversidade, se destaca o fato que das 13708 espécies de angiospermas listadas para o Domínio Mata Atlântica, cerca de 1/4 (3592) ocorrem em formações campestres e 918 dessas são endêmicas desse domínio (Stehmann et al. 2009), em que pese a pequena proporção de área de ocorrência dos campos em relação às formações florestais. Além disso, das 995 espécies ocorrentes em afloramentos rochosos, 416 são endêmicas (Stehmann et al. 2009). Tomados em conjunto, esses números indicam que cerca de $20 \%$ dos endemismos do Domínio Mata Atlântica ocorrem em formações campestres e/ou em afloramentos rochosos.

Como exemplo da dimensão da diversidade taxonômica dos campos rupestres, se estima que a flora da Cadeia do Espinhaço detenha mais de 4000 espécies (Giulietti et al. 1997), sendo que esse valor parece marcadamente subestimado, ao se confrontar com os valores apresentados para as poucas localidades que foram inventariadas extensivamente (Rapini et al. 2008). Além disso, muitas das novas descrições taxonômicas são para estes ambientes, estimando-se que $1 / 4$ das espécies novas descritas no Brasil entre 1997 2002 foi proveniente dos campos rupestres (Zappi et al. 2002). Outro aspecto é que via de regra inventários em áreas próximas resultam em novidades taxonômicas expressivas, por exemplo, sete espécies novas de Asteraceae foram descritas para uma área de campos rupestres na Bahia, distante apenas $80 \mathrm{~km}$ de outra em que já haviam sido descritas 42 espécies desta família (Rapini et al. 2008). Isso exemplifica a alta diversidade regional encontrada nos campos rupestres, assim como nos campos de altitude.

Tais características, em muito influenciadas pela distribuição disjunta dessas formações, significam alta vulnerabilidade da flora dos complexos rupestres como um todo, o que se reflete em muitas espécies sob ameaça de extinção. Apesar de aparentemente apresentarem alta resistência a fatores de impacto e estresse como pastoreio pelo gado, incêndios recorrentes e a outras condições, que inclusive explicam sua ocorrência, como escassez de água e nutrientes (Giulietti et al. 1997, Ribeiro \& Fernandes 2000, Safford 2001, Benites et al. 2007), as vegetações e espécies dos complexos rupestres de altitude são fortemente sensíveis à conversão de habitat. As principais ameaças incidentes sobre estas vegetações são partilhadas por outros ecossistemas de montanhas tropicais e foram agrupadas por Martinelli (2007) em erosão e instabilidade do solo devido atividades antropogênicas; desmatamento de áreas tampão adjacentes, facilitando a invasão biológica; baixa competitividade da flora local em relação aos invasores; queimadas; retirada de espécies ornamentais; mineração e infraestrutura de energia e comunicações; expansão urbana e alta susceptibilidade às mudanças climáticas. Devido a áreas de distribuição naturalmente pequenas, a simples instalação de um condomínio ou de uma monocultura de pinheiros (Pinus spp.) ou pasto de braquiária, por exemplo, em uma vertente montanhosa pode deixar espécies de campos rupestres e de altitude vulneráveis ou mesmo levá-las à extinção.

\section{Espécies ameaçadas de extinção nos campos rupestres e campos de altitude}

A mais recente lista oficial brasileira de espécies de plantas ameaçadas de extinção (Instrução Normativa MMA n ${ }^{\circ}$ 06, setembro de 2008) incluiu 472 espécies como ameaçadas e outras 1079 como potencialmente ameaçadas, mas sem dados suficientes para avaliação objetiva (categoria DD - dados deficientes). Os dois componentes da lista estão certamente subestimados, se considerarmos, por exemplo, as cerca de 100 espécies descritas anualmente para a Mata Atlântica (Stehmann et al. 2009) e a quantidade de espécies novas descritas nos últimos 10 anos em ambientes extremamente ameaçados por atividades impactantes, como as cangas do Quadrilátero Ferrífero (Jacobi \& Carmo 2008). Além disso, a lista oficial não é consensual na comunidade científica e outras fontes listam até três vezes mais espécies de plantas sob ameaça no país. Como exemplo para a situação dos campos rupestres, das 472 espécies oficialmente reconhecidas como ameaçadas, 126 ocorrem no Estado de Minas Gerais, sendo a grande maioria destas associadas às elevações quartzíticas. Já em relação às plantas do Domínio Mata Atlântica, das 238 espécies reconhecidas como ameaçadas, 42 ocorrem em formações campestres e afloramentos e considerando os Anexos I e II, um total de 187 espécies encontram-se nestes ambientes, sendo que 148 (ca. 80\%) são exclusivas de campos e afloramentos (q.v., Stehmann et al. 2009).

Existem numerosos casos bem documentados de espécies desses ambientes com distribuição bastante restrita e que são encontradas em parte ou integralmente fora de unidades de conservação de proteção integral (e.g., Coccoloba cereifera Schw. (Ribeiro \& Fernandes 2000); Encholirium agavoides Forzza \& Zappi (Forzza \& Zappi 2010); Vellozia gigantea N.L. Menezes \& Mello-Silva (Mello-Silva \& Menezes 1999)). A conservação dessas espécies em muito depende, direta ou indiretamente, das proteções atualmente conferidas pelo Código Florestal e, portanto, seriam severamente afetadas pela inexigibilidade de reserva legal em propriedades pequenas e pela redução de APPs. Casos assim envolvem, inclusive, espécies que embora não tenham sido listadas oficialmente como ameaçadas estão sob forte risco, tal como Gaultheria sleumeriana Kin.-Gouv., que é endêmica dos campos da Serra da Bocaina e cuja população registrada não ultrapassa 50 indivíduos adultos (Freitas et al. 2006), sendo que apenas três destes dentro do Parque Nacional da Serra da Bocaina (L. Freitas, obs. pess.). Outro caso emblemático é Worsleya rainieri (J.D.Hooker) Traub. \& Moldenke, espécie endêmica dos campos de altitude da Serra dos Órgãos (Martinelli 1996), com hábitat altamente específico e populações geneticamente únicas (Moraes 
2009). Apenas quatro dos 21 sítios de ocorrência dessa espécie são bem preservados e mais de $50 \%$ dos remanescentes populacionais estão expostos a diferentes tipos de ameaça, afetando a persistência da espécie na natureza; apesar de todos os sítios estarem em unidades de conservação, até recentemente todos eles se localizavam em unidades de uso sustentável (Moraes 2009 - três sítios de ocorrência foram abarcados com a expansão da ReBio Araras, M. A. Moraes, com. pess.).

A ocorrência disjunta das vegetações dos campos rupestres e campos de altitude faz com que a distribuição de suas espécies seja naturalmente fragmentada, situação em que se recomenda estratégias de conservação com base na teoria de metapopulações (Hanski \& Simberloff 1997). Assim, o conceito do tamanho mínimo viável para uma população (i.e., número mínimo de indivíduos em uma população para sua persistência em um período de tempo amplo) é complementado com a ideia do número mínimo de populações (i.e., número mínimo de populações para a persistência da metapopulação a longo prazo). Ambos conceitos exigem conhecimento da história de vida de cada espécie em particular e monitoramento de sua dinâmica populacional em diferentes fragmentos, inclusive naqueles com condições adequadas para ocorrência da espécie, mas que não a apresenta em determinado momento. Para a grande maioria das espécies dos campos, em destaque para as espécies raras, não se dispõem de dados para estimativas que permitam indicar, mesmo que com baixa precisão, um número mínimo e quais populações precisam ser protegidas para a persistência das metapopulações. Os poucos estudos sobre estrutura genética de populações de espécies de afloramentos e campos mostram alta estruturação, o que indica baixo fluxo gênico (Barbará et al. 2008) e necessidade de proteção a um grande número de populações. Assim, a retirada da proteção dada pelas APPs aos topos de morros e altas elevações pode trazer danos sérios ou irreversíveis à perpetuação de numerosas espécies.

As montanhas abrigam muitas das unidades de conservação do sudeste e sul do país. No entanto, largas extensões são atualmente protegidas por Áreas de Proteção Ambiental (APA), cuja efetividade para a conservação da biodiversidade se baseia, em grande parte, na aplicação cotidiana do Código Florestal, como na delimitação das Zonas de Proteção da Vida Silvestre. São exemplos de extensas APAs que embarcam regiões montanhosas, as APA da Mantiqueira (Serra da Mantiqueira, SP, MG, RJ, com 422 mil ha), APA Morro da Pedreira (Serra do Espinhaço, MG, com 112 mil ha) e a APA Sul (Serra do Espinhaço - Quadrilátero Ferrífero, MG, com 166 mil ha). Silva et al. (2008) analisaram a representatividade das áreas protegidas na Reserva da Biosfera da Serra do Espinhaço, que cobre a porção mineira desta extensa cadeia e em que se inserem as duas últimas APAs citadas. Verificaram que 271 objetos de conservação $(41,8 \%$ do total, entre espécies da flora e da fauna e tipos de vegetação) não estão adequadamente protegidos na região. Segundo esses autores, por meio de modelagem que otimiza o desenho de áreas protegidas, para que houvesse uma proteção minimamente adequada, seria necessário incluir outras 27 áreas no sistema de áreas protegidas do Espinhaço (que tem apenas 2,6\% de seu território em unidades de conservação de proteção integral). Esta situação se agrava, ou a estratégia de conservação se tornará ainda mais custosa, se as APAs se tornarem menos efetivas na proteção das espécies ali presentes.

\section{Dispensa de reserva legal para pequenas propriedades}

Dada a imensa heterogeneidade espacial das regiões montanhosas em geral, que se reflete no elevado número de endemismos, ganho expressivo em conservação se daria com a adequada distribuição das reservas legais, de modo a abarcar parte desta variação. Enquanto as APPs têm certa rigidez locacional, isto é, sua relação com a paisagem é pré-definida em lei, a reserva legal pode ser localizada na propriedade de modo a harmonizar produção (e.g., evitando porções mais férteis) com estratégias de otimização da conservação, somando-se outras reservas legais ou protegendo ambientes específicos. Assim, as reservas legais têm grande potencial como instrumento de salvaguarda da diversidade de ambientes encontrados nas montanhas, mesmo antes de conhecê-los em detalhe, como proposto por Nascimento (2010) para os campos rupestres da Serra do Espinhaço. A partir de mapas geológicos, pedológicos e de tipos fisionômicos pode-se propor uma distribuição das reservas legais de modo a aumentar a representatividade de cada uma das unidades de paisagem reconhecidas para uma dada porção territorial (i.e., 'regime de condomínio'). Neste sentido, a proposta de obrigatoriedade de reservas legais apenas em propriedades com mais de quatro módulos fiscais tem implicações severas para a conservação das espécies dos complexos rupestres de altitude.

Os módulos fiscais são definidos a partir das zonas típicas de módulo (ZTMs), que são regiões delimitadas pelo INCRA com características ecológicas e econômicas homogêneas e considerando a divisão micro-regional do IBGE a partir de influências demográficas e econômicas de grandes centros urbanos. De acordo com a Lei 8629 de 1993, o imóvel rural com área inferior a um módulo fiscal é classificado como minifúndio e com área compreendida entre um e quatro módulos fiscais como pequena propriedade. O INCRA (2010) define o módulo mínimo rural por região de acordo com as atividades predominantes desenvolvidas (lavouras temporárias, lavouras permanentes, criação de animais, reflorestamentos, ou ainda atividades indefinidas). O tamanho do módulo leva também em consideração a fertilidade do solo, a proporção de terras consideradas imprestáveis e/ou protegidas pela legislação ambiental, e a distância para os mercados consumidores (Tabela 1).

Tabela 1. Distribuição de tamanho dos módulos fiscais conforme Zonas Típicas de Módulo (ZTMs), considerando a região e o tipo de exploração. Valores em ha.

Table 1. Size distribution of the "land tax units" according to "Typical Module Zones" (ZTMs), considering the region and type of land use. Figures in ha.

\begin{tabular}{ccccccc}
\hline $\begin{array}{c}\text { Código da } \\
\text { ZTM }\end{array}$ & ZTM & $\begin{array}{c}\text { Hortifruti- } \\
\text { granjeira }\end{array}$ & $\begin{array}{c}\text { Lavoura } \\
\text { permanente }\end{array}$ & $\begin{array}{c}\text { Lavoura } \\
\text { temporária }\end{array}$ & $\begin{array}{c}\text { Pecuária } \\
\text { Imóvel } \\
\text { inexplorado/florestal }\end{array}$ \\
\hline 1 & A1 & 2 & 10 & 13 & 30 & 45 \\
2 & A2 & 2 & 13 & 16 & 40 & 60 \\
3 & A3 & 3 & 15 & 20 & 50 & 60 \\
4 & B1 & 3 & 16 & 20 & 50 & 80 \\
5 & B2 & 3 & 20 & 25 & 30 & 90 \\
6 & B3 & 4 & 25 & 35 & 90 & 110 \\
7 & C1 & 4 & 35 & 45 & 110 & 115 \\
8 & C2 & 5 & 40 & 50 & & 110 \\
\end{tabular}


As ZTMs são definidas caracterizando municípios inteiros, de modo a facilitar a aplicação da lei. Para os municípios das regiões sul e sudeste, não há casos que chegam ao extremo de ZTMs de 100 ha, mas é bastante comum o valor de 30 ha, resultando em propriedades com mais de 100 ha que são entendidas como pequenas (Figura 1). Especificamente para os municípios mineiros na Serra da Mantiqueira que abrigam campos de altitude e na Serra do Espinhaço com campos rupestres, o módulo fiscal é de até 30 ha na maioria dos casos (Tabela 2). Por exemplo, em Conceição do Mato Dentro, na Serra do Espinhaço, município com grande pressão de silvicultura, pastagens de braquiária e criação de bubalinos, o módulo fiscal é de 30 ha e o tamanho médio das propriedades era de 91,7 ha em 1996 (SEBRAE 2000). Assim, nesse caso, a proposta de dispensa de reserva legal em propriedades com até quatro módulos (i.e., até 120 ha) descaracteriza todo o sistema de proteção da biodiversidade com base na ideia da paisagem em mosaico e fortalece o modelo de paisagem de contrastes, que leva a uma exigência de criação de numerosas novas unidades de conservação de proteção integral, com multiplicação de custos para o estado, acirramento de conflitos e redução tanto da proteção da biodiversidade como da sustentabilidade da produção agropecuária.
Nas áreas montanhosas do país, com vegetação predominantemente campestre, é comum o uso da terra para criação extensiva de gado e, crescentemente, para silvicultura (e.g., Pinus spp. e Eucalyptus spp.), atividades que correspondem aos maiores módulos fiscais, que podem chegar, respectivamente, a 100 e 110 ha (INCRA 2010). Criação extensiva de gado em campos com espécies nativas é um uso que em certa medida mantém a diversidade de espécies nos campos. Porém, a substituição por pastos de espécies exóticas e o plantio de pinheiros ou eucaliptos têm efeitos desastrosos sobre a biota campestre, potencializados com a eliminação das pequenas manchas de vegetação nativa, no caso de dispensa de implementação de reserva legal. Nos estados do sul do país é comum o arrendamento das áreas de diversos proprietários para plantio de Pinus spp., resultando em extensas áreas com monocultura de um mesmo empreendedor, apesar das propriedades não serem tão grandes (S. Ziller, com. pess.). Espécies desse gênero já vêm causando severos danos nas regiões campestres do sul do país e em outros países do Cone Sul e de outros continentes (Richardson et al. 2008). Pastagens também têm representado conversão de habitat, com plantio de forrageiras exóticas, substituindo o antigo manejo dos chamados 'campos nativos', muitos deles campos de espécies nativas manejados com fogo para evitar a recuperação das matas originais (Behling \& Pillar 2007)

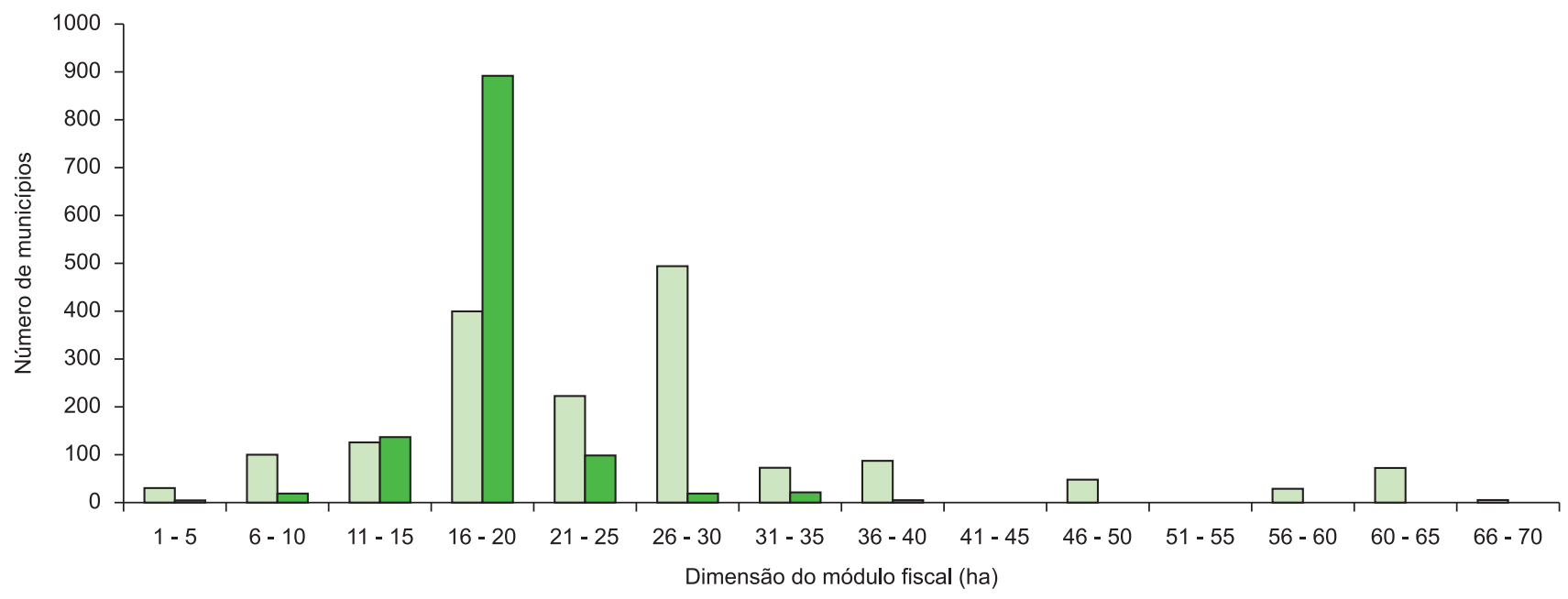

Figura 1. Número de municípios por dimensão da zona típica de módulo na região sudeste (barras verde claro) e na região sul (barras em verde escuro) brasileiras. Na região sul a moda está em 20 ha, i.e., em torno de 1000 municípios com pequenas propriedades entendidas como aquelas com áreas de até 80 ha. Na região sudeste a maior frequência é de municípios com zona tipica de módulo de 30 ha.

Figure 1. Number of counties arranged by size of the "Typical Module Zones" in southeastern (light green bars) and southern (dark green bars) Brazil. In the southern, the mode is 20 ha, i.e., about 1000 counties, which small properties are those with areas up to 80 ha. In the southeastern, counties with "Typical Module Zones" of 30 ha are the most frequent.

Tabela 2. Tamanho de módulo fiscal de onze municípios em região montanhosa do Estado de Minas Gerais (fonte: www.faemg.org.br).

Table 2. Size of the "land tax units" of eleven counties in the montane region of Minas Gerais State (source: www.faemg.org.br).

\begin{tabular}{lcc}
\hline \multicolumn{1}{c}{ Município } & Dimensão do módulo fiscal (ha) & Vegetação campestre presente no município \\
\hline Conceição do Mato Dentro & 20 & Rupestre \\
Itabira & 20 & Rupestre \\
Itambé do Mato Dentro & 20 & Rupestre \\
Jaboticatubas & 20 & Rupestre \\
Alto Caparaó & 24 & Altitude \\
Aiuruoca & 30 & Altitude \\
Passa Quatro & 30 & Altitude \\
Itamonte & 30 & Altitude \\
Diamantina & 40 & Rupestre \\
Serro & 40 & Rupestre \\
Grão Mogol & 50 & Rupestre \\
\hline
\end{tabular}


A proposta de dispensa de exigência de reserva legal para pequenas propriedades tem claramente um viés social, mas pode ter elevado custo para estes mesmos supostos beneficiários da dispensa, que deixam de contar com os diversos aportes da biodiversidade que não são computados na contabilidade tradicional, como a trivial água limpa, a contenção da erosão, as plantas medicinais e a polinização das culturas. A contabilização deste PIB que não passa diretamente pelo fluxo de caixa do país (com incorporação destes benefícios em cálculos de IDH, por exemplo) tem sido proposto por diversos economistas (revisão em Scarano 2007), como forma de inserir este componente na avaliação da sustentabilidade do modelo de desenvolvimento escolhido.

\section{Supressão das APPs em topos de morros e elevações e redução da faixa de mata ciliar}

As áreas acima de 1800 m no Brasil estão basicamente restritas à região sudeste e aos Estados do Amazonas e Roraima (além dos picos da Serra do Ibitiraquire no Paraná, da Serra Geral em Santa Catarina e da Serra dos Barbados e Serra das Almas na Bahia). A partir dos dados de elevação obtidos junto ao SRTM ("Shuttle Radar Topography Mission") - (Hijmans et al. 2005), a área total dessas elevações no Brasil representa aproximadamente $1100 \mathrm{~km}^{2}$ apenas (M.F. Siqueira, com. pess.). Os solos associados aos campos rupestres e de altitude são em geral rasos, arenosos, com alta saturação de alumínio e teores variados de matéria orgânica (Benites et al. 2007). Dadas as condições topográficas e de baixa fertilidade dos solos, as áreas em topos de morro e em altas elevações são inadequadas para a agricultura, com baixo nível de rentabilidade e sustentabilidade das culturas. Apesar disso, algumas atividades vêm se expandindo nas regiões montanhosas do país, além dos já citados plantios de espécies forrageiras e madeireiras exóticas. Por exemplo, a criação de ovinos e o plantio de frutíferas de ambientes temperados e alto valor de mercado (como 'berries') têm gerado a conversão de habitat em campos de altitude na Serra da Mantiqueira, inclusive em áreas acima de $1800 \mathrm{~m}$ de altitude. Soma-se a isso a pressão de parcelamento do solo e loteamentos, como mais evidente nas proximidades dos grandes centros urbanos (Moraes 2009).

A criação de uma faixa de APP de 15 m de largura para os córregos com leito de até $5 \mathrm{~m}$ de largura, busca atender a uma demanda de produtores, principalmente daqueles com terras pouco férteis, para quem os terrenos próximos aos rios são de especial valor. Nas montanhas, com muitas nascentes e rios, faixas largas de APP podem confinar significativamente a área passível de conversão de uma propriedade. No entanto, a soma dos efeitos da redução em $50 \%$ das faixas de APPs na maioria dos rios de montanha com a dispensa de reserva legal para muitas propriedades e a eliminação da figura da APP para áreas acima de $1800 \mathrm{~m}$ e em topos de morros resultaria em perdas potenciais excessivas para os complexos rupestres de altitude. Essa porção territorial é de especial interesse para a conservação sob vários aspectos, como recarga e regulação hídrica, contenção da erosão e do assoreamento, riqueza de espécies e endemismos e valores recreativos e espirituais, sendo que as perdas com a conversão de habitat que pode advir das mudanças no Código Florestal são desproporcionais ao potencial benefício econômico, mesmo a curto e médio prazo. Além disso, as elevações nas temperaturas médias previstas para este século no Brasil (Marengo 2007) podem implicar em pronunciado aumento nas taxas de extinção nas vegetações de campos rupestres e campos de altitude, pelo simples fato que não haverá possibilidade de migração para altitudes mais altas em que as temperaturas equivalham às encontradas nas atuais áreas de distribuição. Isso coloca os refúgios montanos entre os cinco ecossistemas terrestres brasileiros mais vulneráveis às mudanças climáticas globais (CONABIO 2007). Somase a isso, a projeção de ocupação de áreas mais elevadas por culturas como o café com o aumento da temperatura (Assad et al. 2004), o que ampliaria as pressões sobre as vegetações de áreas montanhosas de ambientes em altitudes. Tal cenário exige ações e mecanismos que fortaleçam a proteção desses ambientes (CONABIO 2007) e não o oposto como proposto no substitutivo ao Código Florestal.

As características ambientais das áreas de topo de morros e altas elevações bem como nas adjacências de rios (i.e., APPs) diferem daquelas encontradas em áreas menos elevadas ou mais distantes dos rios, e consequentemente determinam a ocorrência de fisionomias vegetais diferentes, com composição distinta de flora e fauna. Assim, com a redução das APPs, áreas em propriedades médias e grandes que até então são mantidas preservadas devido a seu status de APP, podem ser contabilizadas como áreas de reserva legal e isso levaria a um aumento na pressão sobre os remanescentes de formações florestais montanas e altomontanas adjacentes às vegetações campestres, bem como sobre $o$ cerrado e florestas semidecíduas, por exemplo, que hoje restam com reserva legal. Além das perdas mais evidentes devido à composição de espécies distinta que as diferentes formações abrigam, tal cenário é prejudicial do ponto de vista de funcionamento ecossistêmico, uma vez que diferentes formações desempenham funções complementares. Por exemplo, os recursos florais (néctar) produzidos pelas espécies de campos de altitude na Serra da Bocaina são insuficientes para manter as populações de beija-flores o ano todo (Freitas \& Sazima 2006). Assim, a fonte de alimento dos beija-flores nessa área é formada por um conjunto de espécies dos campos e das florestas de Araucaria e altomontanas. Nesse caso, mesmo com a preservação das áreas de campo, a redução das áreas de floresta poderia ter um efeito cascata na reprodução sexual de plantas ornitófilas dos campos e na dinâmica populacional dos beija-flores, sendo que ao menos para Stephanoxis lalandi (Vieillot, 1818) isso poderia ser catastrófico, já que no sudeste esta espécie é endêmica das partes mais elevadas da Serra da Mantiqueira e Serra do Mar. Em suma, a supressão das APPs em topos de morros e em elevações e sua redução nas matas ciliares afetariam a importante distinção entre APPs e reservas legais como instrumentos complementares para manutenção da heterogeneidade biológica em escala de paisagem (Metzger 2010).

\section{Considerações Finais}

"A conservação em países de megadiversidade enfrenta o desafio de evitar a perda de espécies que sequer conhecemos" - esta frase de Lewinsohn \& Prado (2005, pag. 41) orienta as considerações aqui feitas. Muitas das mudanças propostas no substitutivo ao Código Florestal parecem partir do princípio de que há grande prejuízo individual em nome de um benefício coletivo muito difuso, por exemplo, a dispensa de criação de reserva legal em propriedades com área aquém de quatro módulos fiscais. Essas alterações não consideram os benefícios diretos aos proprietários advindos, no médio e longo prazo, da manutenção de porções de vegetação nativa no interior de cada propriedade e não são compreendidos os benefícios de uma paisagem em mosaico.

Com os instrumentos propostos pelo substitutivo opta-se, em última instância, por paisagem de fortes contrastes (i.e., áreas integralmente protegidas, como parques e reservas biológicas, com implementação beneficiada pela figura da compensação da reserva legal, pontuando extensas áreas de propriedades desprovidas de vegetação nativa, exceto magras matas ciliares). Com isso, se aniquila as possibilidades de manter níveis adequados de fluxo de espécies nativas através dos fragmentos preservados na paisagem. Tal cenário é prejudicial tanto para a conservação da biodiversidade como para a produção agropecuária, principalmente dos pequenos produtores, que se beneficiam dos serviços ambientais, tais como oferta de água, presença de polinizadores, controladores naturais de pragas e recursos madeireiros e não-madeireiros, incluindo espécies medicinais. 
O texto do substitutivo tem diversos trechos em que se descrevem possibilidades de maior proteção quando a atividade prevista afeta espécies ameaçadas de extinção. Por exemplo, no Art. $21, \S 2^{\circ}$, temse: "Nas áreas passíveis de uso alternativo do solo, a supressão da vegetação que abrigue espécies da fauna ou da flora ameaçadas de extinção, segundo lista oficial publicada pelos órgãos federal ou estadual competentes do SISNAMA, dependerá da adoção de medidas compensatórias ou mitigadoras que assegurem a conservação da espécie". Essas possibilidades de maior proteção seriam adequadas se tivéssemos amplo conhecimento de nosso território e de nossa biota, mas somos país extremamente biodiverso. Como estimado por Lewinsohn \& Prado (2005), com uma taxa de descrição de 1500 espécies por ano, levaríamos ao menos oito séculos para ter um catálogo completo das espécies do país, o que não considera o esforço necessário para ter conhecimentos que subsidiassem análises do estado de conservação e prioridades de conservação destas mesmas espécies.

Analisando a lista oficial da flora ameaçada do país (Instrução Normativa MMA n ${ }^{\circ}$ 06, 2008), vemos que de uma primeira proposta de aproximadamente cinco mil espécies candidatas à categorização como ameaçadas de extinção, elaborada com base em conhecimento de campo dos pesquisadores que as sugeriram, 472 foram oficialmente reconhecidas como ameaçadas de extinção. Porém, para um alarmante conjunto de 1079 espécies entendeu-se que se tinha uma percepção da ameaça, mas falta de dados objetivos que dessem substância a tal classificação, de acordo com parâmetros internacionais de categorização de risco de extinção de espécies, como os propostos pela IUCN (Mace et al. 2008). Estes números evidenciam as imensas lacunas de conhecimento que não serão superadas no curto ou médio prazo, e talvez nem mesmo no longo prazo, e tornam inquestionável o acionamento do 'princípio da precaução', que não aparece neste substitutivo.

A distribuição do esforço de proteção na sociedade é benéfica para toda a sociedade, mesmo que não aparente no curto prazo. A correta aplicação do Código Florestal vigente teria reduzido a necessidade de criação de unidades de conservação de proteção integral, que são indispensáveis no quadro de crise da biodiversidade, mas que têm um custo imediato de implementação que não é baixo para a sociedade e é alto para as pessoas diretamente afetadas, que muitas vezes são justamente as que menos contribuíram para o processo de descaracterização que motivou a criação da unidade de conservação. A distribuição dos esforços de proteção nas muitas propriedades pode ser vista como uma ferramenta de distribuição de benefícios bem como de prejuízos, ou seja, uma importante política pública.

Caso não se venha a reverter esta tendência de redução ainda maior das áreas protegidas, um caminho a percorrer será o do reforço no investimento em conhecimento da biodiversidade e graus de ameaça, de modo a subsidiar decisões de proteção caso a caso, que são custosas para a sociedade, não pelo investimento em conhecimento, mas pela geração de numerosos instrumentos normativos e legais que dificultam a vida do cidadão, das entidades e das instituições.

\section{Agradecimentos}

Ao Henri Dubois Collet por ter chamado à atenção do primeiro autor para a relação entre módulos rurais e fiscais e conservação da biodiversidade; à Marinez Ferreira de Siqueira pela confecção de mapa, cálculo de área do território brasileiro acima de $1800 \mathrm{~m}$ e esclarecimentos. LF é bolsista de produtividade do CNPq.

\section{Referências Bibliográficas}

AB'SABER, A.N. 1996. Introdução. In Campos de altitude (G. Martinelli). $2^{\mathrm{a}}$ ed. Editora Index, Rio de Janeiro, p.15-29.

ASSAD, E.D., PINTO, H.S., ZULLO JR, J. \& AVILA, A.M.H. 2004. Impacto das mudanças climáticas no zoneamento agroclimático do café no Brasil. Pesq. Agropec. Bras. 39:1057-1064.
BARBARÁ, T., LEXER, C., MARTINELLI, G., MAYO, S., FAY, M.F. \& HEUERTZ, M. 2008. Within-population spatial genetic structure in four naturally fragmented species of a neotropical inselberg radiation, Alcantarea imperialis, A. geniculata, A. glaziouana and A. regina (Bromeliaceae). Heredity 101:285-296.

BEHLING, H. \& PILLAR, V.P. 2007. Late quaternary vegetation, biodiversity and fire dynamics on the southern Brazil highland and their implication for conservation and management of modern araucaria forest and grassland ecosystems. Phil. Trans. Soc. B 362:243-251.

BENITES, V.M., CAIAFA, A.N., MENDONÇA, E.S., SCHAEFER, C.E. \& KER, J.C. 2003. Solos e vegetação nos Complexos Rupestres de Altitude da Mantiqueira e do Espinhaço. Flor. Amb. 10:76-85.

BENITES, V.M., SCHAEFER, C.E.G.R., SIMAS, F.N.B. \& SANTOS, H.G. 2007. Soils associated with rock outcrops in the Brazilian mountain ranges Mantiqueira and Espinhaço. Rev. Bras. Bot. 30:569-577.

COELHO, F.F., CAPELO, C., NEVES, A.C.O. \& FIGUEIRA, J.E.C. 2007. Vegetative propagation strategies of four rupestrian species of Leiothrix (Eriocaulaceae). Rev. Bras. Bot. 30:687-694.

Comissão Nacional de Biodiversidade - CONABIO. 2007. Sugestões do Conselho Nacional de Biodiversidade para medidas de adaptação de biodiversidade às mudanças climáticas. CONABIO, Brasília, (Resolução do CONABIO em 25/abr/2007).

CONCEIÇÃO, A.A. \& PIRANI, J.R. 2005. Delimitação de hábitats em campos rupestres na Chapada Diamantina, Bahia: substrato, composição florística e aspectos estruturais. Bol. Bot. Univ. São Paulo 23:85-111.

CORTIZO, S. 2007. Topo de morro na resolução CONAMA no 303. http:// www.isfx.com.br/artigos/topo.pdf (último acesso em 30/01/2010).

FERRI, M.G. 1980. Vegetação brasileira. $1^{\mathrm{a}}$ ed. USP, São Paulo.

FORZZA, R.C. \& ZAPPI, D. 2010. Side by side: two remarkable new species of Encholirium Mart. ex Schult. \& Schult.f. (Bromeliaceae) found in the Cadeia do Espinhaço, Minas Gerais, Brazil. Kew Bull. (no prelo).

FREITAS, L. \& SAZIMA, M. 2006. Pollination biology in a tropical highaltitude grassland in Brazil: interactions at the community level. Ann. Miss. Bot. Gard. 93:465-516.

FREITAS, L., GALETTO, L. \& SAZIMA, M. 2006. Pollination by hummingbirds and bees in eight syntopic species and a putative hybrid of Ericaceae in southeastern Brazil. Pl. Syst. Evol. 258:49-61.

GEISE, L., PEREIRA, L.G., BOSSI, D.E.P. \& BERGALLO, H.G. 2004. Pattern of elevational distribution and richness of non volant mammals in Itatiaia National Park and its surroundings, in Southeastern Brazil. Braz. J. Biol. 64:599-612.

GIULIETTI, A.M. \& PIRANI, J.R. 1988. Patterns of geographic distribution of some plant species from the Espinhaço range, Minas Gerais and Bahia. In Proceedings of a Workshop of a Neotropical Distribution Patterns (W.R. Heyer \& P.E. Vanzolini, eds). Academia Brasileira de Ciências, Rio de Janeiro, p.39-69.

GIULIETTI, A.M., PIRANI, J.R. \& HARLEY, R.M. 1997. Espinhaço Range Region, Eastern Brazil. In Centres of plant diversity. The Americas (S.D. Davis, V.H. Heywood, O. Herrera-MacBryde, J. Villa-Lobos \& A.C. Hamilton, eds.). World Wide Fund For Nature, Oxford, vol.3, p.397-404.

HANSKI, I. \& SIMBERLOFF, D. 1997. The metapopulation approach, its history, conceptual domain, and application to conservation. In Metapopulation Biology (I.A. Hanski \& M.E. Gilpin, eds.). Academic Press, San Diego, p.5-26.

HIJMANS, R.J., CAMERON, S.E., PARRA, J.L., JONES, P.G. \& JARVIS, A. 2005. Very high resolution interpolated climate surfaces for global land areas. Int. J. Climat. 25:1965-1978.

Instituto Nacional de Colonização e Reforma Agrária - INCRA. 2010. Indicadores cadastrais. http://200.252.80.30/_htm/serveinf/_htm/indic. htm\#indic3. (último acesso em 05/11/2010).

JACOBI, C.M. \& Carmo, F.F. 2008. The contribution of ironstone outcrops to plant diversity in the Iron Quadrangle, a threatened Brazilian landscape. AMBIO 37:324-326.

LEWINSOHN, T. \& PRADO, P.I. 2005. Quantas espécies há no Brasil? Megadiversidade 1:36-42. 
MACE, G.M., COLLAR, N.J., GASTON, K.J., HILTON-TAYLOR, C., AKÇAKAYA, H.R., LEADER-WILLIAMS, N., MILNER-GULLAND, E.J. \& STUART, S.N. 2008. Quantification of extinction risk: IUCN's system for classifying threatened species. Cons. Biol. 22:1424-1442.

MARENGO, J.A. 2007. Mudanças climáticas e seus efeitos sobre a biodiversidade: caracterização do clima atual e definição das alterações climáticas para o território brasileiro ao longo do século XXI. Série Biodiversidade No. 26, MMA, Brasília.

MARTINELLI, G. 1996. Campos de altitude. $2^{\mathrm{a}}$ ed. Editora Index, Rio de Janeiro.

MARTINELLI, G. 2007. Mountain biodiversity in Brazil. Rev. Bras. Bot. 30:587-597.

MELLO-SILVA, R. \& MENEZES, N.L. 1999. Two new Brazilian Velloziaceae, Vellozia auriculata and Vellozia gigantea, and a key to the related Dracenoid species of Vellozia. Novon 9:536-541.

METZGER, J.P. 2010. O Código Florestal tem base científica? Natur. Cons. 8:92-99.

MORAES, M.A. 2009. Conservação e manejo de Worsleya rayneri (Amaryllidaceae): uma espécie de campos de altitude ameaçada de extinção. Dissertação de mestrado, Jardim Botânico do Rio de Janeiro, Rio de Janeiro.

NASCIMENTO, J.S. 2010. Estudo da paisagem como base para o desenvolvimento e monitoramento de estratégias de conservação, com uso de análise multicriterial, em ambiente SIG, no mosaico de Unidades de Conservação da Serra do Cipó, MG. Dissertação de mestrado, Universidade Federal de Minas Gerais, Belo Horizonte.

OLIVEIRA-FILHO, A.T. \& FONTES, M.A.L. 2000. Patterns of floristic differentiation among Atlantic forests in Southeastern Brazil and the influence of climate. Biotropica 32:793-810.

POREMBSKI, S. 2007. Tropical inselbergs: habitats types, adaptive strategies and diversity patterns. Rev. Bras. Bot. 30:579-586.

RAPINI, A., RIBEIRO, P.L., LAMBERT, S. \& PIRANI, J.R. 2008. A flora dos campos rupestres da Cadeia do Espinhaço. Megadiversidade 4:16-24.

RIBEIRO, K.T. \& FERNANDES, G.W. 2000. Patterns of abundance of a narrow endemic species in a tropical and infertile habitat. Pl. Ecol. 147:205-218

RIBEIRO, R.F. 2005. Florestas anãs do sertão: o Cerrado na história de Minas Gerais. Autêntica Editora, Belo Horizonte.

RICHARDSON, D.M., VAN WILGEN, B.W. \& NUNEZ, M.A. 2008. Alien conifer invasions in South America: short fuse burning? Biol. Invas. 10:573-577.
SAFFORD, H.D. 1999a. Brazilian Páramos. I. An introduction to the physical environment and vegetation of the campos de altitude. J. Biogeogr. 26:693-712.

SAFFORD, H.D. 1999b. Brazilian Páramos. II. Macro- and mesoclimate of the campos de altitude and affinities with high mountain climates of the tropical Andes and Costa Rica. J. Biogeogr. 26:713-737.

SAFFORD, H.D. 2001. Brazilian Páramos. III. Patterns and rates of postfire regeneration in the campos de altitude. Biotropica 33:282-302.

SCARANO, F.R. 2007. Perspectivas das ciências da biodiversidade no Brasil. Sci. agric. 64:439-447.

SCHAEFER, C.E.R., MICHEL, R.F.M., CHAGAS, C.S., FERNANDES FILHO, E.I., VALENTE, E.L., SOUZA, E., VASCONCELOS, B.N.F. \& RIBEIRO, A.S.S. 2008. Relatório do levantamento pedológico, geomorfológico e geológico para o Plano de Manejo do Parque Nacional da Serra do Cipó e APA Morro da Pedreira. UFV/DPS, Viçosa.

Secretariado da Convenção sobre Diversidade Biológica - SCDB. 2010. Panorama da biodiversidade global 3. MMA, Brasilia.

SEMIR, J. 1991. Revisão taxonômica de Lychnophora Mart. (Vernoniaeae: Compositae). Tese de doutorado, Universidade Estadual de Campinas, Campinas.

Serviço Brasileiro de Apoio às Micro e Pequenas Empresas - SEBRAE. 2000. Diagnóstico Municipal: Conceição do Mato Dentro. http://www. sebraemg.com.br/arquivos/programaseprojetos/Desenvolvimentolocal/ diagnosticosmunicipais/Concei\%C3\%A7\%C3\%A3o\%20do\%20Mato\% 20Dentro.pdf. (último acesso em 11/11/2010).

SILVA, J.A., MACHADO, R.B., AZEVEDO, A.A., DRUMOND, G.M., FONSECA, R.L., GOULART, M.F., JUNIOR, E.A.M., MARTINS, C.S. \& RAMOS-NETO, M.B. 2008. Identificação de áreas insubstituíveis para conservação da Cadeia do Espinhaço, estados de Minas Gerais e Bahia, Brasil. Megadiversidade 4:270-309.

STEHMANN, J.R., FORZZA, R., SALINO, A., SOBRAL, M., COSTA, D.P. \& KAMINO, L.H.Y. 2009. Plantas da Floresta Atlântica. Jardim Botânico do Rio de Janeiro, Rio de Janeiro.

ZAPPI, D.C., LUCAS, E., STANNARD, B.L., LUGHADHA, E., PIRANI, J.R., QUEIROZ, L.P., ATKINS, S., HIND, N., GIULIETTI, A.M., HARLEY, R.M., MAYO S.J. \& CARVALHO, A.M. 2002. Biodiversidade e conservação na Chapada Diamantina, Bahia: Catolés, um estudo de caso. In Biodiversidade, conservação e uso sustentável da flora do Brasil (E.L. Araújo, A.N. Moura, E.V.S.B. Sampaio, L.M.S. Gestinári \& J.M.T. Carneiro, eds.). Imprensa Universitária, Recife, p.87-89.

Recebido em 16/11/2010

Versão reformulada recebida em 20/12/2010

Publicado em 23/12/2010 